'first-choice' votes alone, when actually a majority prefers $B$ to $A$, and at the same time $C$ is also preferred to $A$ by a majority of the voters. The impact of mathematical thought upon human affairs lags far behind the work of chemistry, electricity and psychology in making a world for man to live in : this matter of elections of various kinds is conspicuously one in which the mathematician should feel his responsibility for making to the national thought that contribution for which his gifts and training fit him.

Proportional representation, a plan lying outside the limits which time set to Prof. Steggall's discussion, deserves from mathematicians (and other's) far more notice than it has yet received; but this is distinctively a method of electing two or more : it has nothing to tell us about the best way to pick out from a number of candidates the one who is preferred to the others individually by the largest majorities of the voters. If twenty such candidates compete for one place, we should regard the contest as 190 duels between one candidate and another : it is surprisingly easy, both for voter and for counter, so to arrange the election that the algebraic sum of every candidate's majorities in his 19 contests emerges directly from a single ballot.

It is safe to forecast that for some centuries to come "Modern Mathematical Problems in Aerodynamics" will be a fruitful meeting-ground for science and mathematics. Prof. H. Levy's researches into the vortex motion set up in the air by the passage through it of an aeroplane's wing deserves something better than the comments of one ignorant of aerodynamics : therefore let it pass unsung, but not unhonoured.

"Should a candidate for School Certificate be allowed to take, in place of the Mathematics and Science Group, a Group containing Drawing and Music and possibly other subjects?" This was the principal subject for general discussion-a somewhat one-sided discussion, because, though on details there was as much divergence of opinion as one would expect, there was but little opposition to the general principle involved, that children well gifted and well taught in subjects of three different kinds should not be classified as educational failures because of weakness in a fourth. Music, drawing, and handicraft constitute a group at present generally inferior for certificatewinning purposes to the other three, which are English subjects, languages, and the science-mathematics group.

This arrangement finds few defenders : some of its opponents are for republican equality between all groups, others for supremacy of one only, the English group. A powerful advocate of this supremacy was Mr. F. H. Knight, who boldly claimed for English subjects the place of honour as most of all a means of access to 'the things of the spirit,' without which other learning will not save the world. Mr. Knight also stressed the educational value of handicraft, not only as being for many children the only form in which solid geometry can be digested, but also for its influence on the development of mind on a wider scale than the mere book-learner can ever appreciate.

Science and mathematics are strong enough to stand on their own merits without needing to entrench their position by decrying the value of other subjects. Generosity, justice, and common sense would alike have been outraged if the Mathematical Association had denied that to the artist his subject is of no less value than is ours to us. Best of all, Demetrius the silversmith was conspicuous by his absence, "which made silver shrines for Diana," and whose trump-card against a rival to his goddess was that "by this craft we have our wealth.", W. HOPE-JoNes.

\section{The Circulation of Seismological Information by Wireless Telegraphy.}

$\mathrm{T}$ a recent issue of NATURE (Dec. 22, p. 968) a short account was given of the existing arrangements for broadcasting early information concerning important earthquakes, and it was announced that the co-operation of American seismological stations would commence this month.

The large earthquake which occurred on Jan. 13 afforded an interesting test of the scheme, and it is satisfactory to record that data from all stations issuing broadcast seismological messages were picked up by the Air Ministry and communicated to Kew Observatory. An eaxly knowledge of the position of the epicentre and of the time of origin was thus obtained. The following table summarises the in. formation received at $\mathrm{Kew}$ :

\begin{tabular}{|c|c|c|c|c|c|}
\hline Station. & $\begin{array}{c}\text { Arrival } \\
\text { of } P \\
\text { G.M.'. }\end{array}$ & $\begin{array}{c}\text { Interval } \\
\left(S^{t}-P\right)\end{array}$ & $\begin{array}{c}\text { Distance } \\
\text { of } \\
\text { Epicentre } \\
\triangle\end{array}$ & $\begin{array}{l}\text { Azimuth of } \\
\text { Epicentre } \\
\text { (from N. } \\
\text { through E). }\end{array}$ & $\begin{array}{c}\text { Time of } \\
\text { origin de- } \\
\text { duced from } \\
(S-P) \text { using } \\
\text { B.A. tables. }\end{array}$ \\
\hline $\begin{array}{l}\text { Kew } \\
\text { Helwan } \\
\text { Bombay } \\
\text { Stonyhurst, } \\
\text { Georgetown } \\
\text { Honolulu } \\
\text { Strasbourg }\end{array}$ & $\begin{array}{llll}\text { h. } & \text { n. } & \text { s. } \\
0 & 14 & 49 \\
0 & 15 & 41 \\
0 & 14 & 12 \\
0 & 14 & 39 \\
0 & 15 & 14 \\
0 & 11 & 32 \\
0 & 14 & 54\end{array}$ & $\begin{array}{rr}\mathrm{m} . & \mathrm{s} . \\
9 & 34 \\
10 & 9 \\
9 & 0 \\
9 & 21 \\
9 & 51 \\
6 & 50 \\
9 & 39\end{array}$ & $\begin{array}{l}\text { Km. } \\
8290 \\
8970 \\
7600 \\
7850 \\
8620 \\
5150 \\
8380\end{array}$ & $\begin{array}{c}19^{\circ} \\
\ldots \\
\ldots \\
330^{\circ} \pm 5^{\circ} \\
330^{\circ} \pm 5^{\circ} \\
\ldots\end{array}$ & $\begin{array}{rrr}\text { h. } & \text { m. } & \text { s. } \\
0 & 3 & 4 \\
0 & 3 & 17 \\
0 & 3 & 5 \\
0 & 3 & 8 \\
0 & 3 & 9 \\
0 & 2 & 50 \\
0 & 3 & 3\end{array}$ \\
\hline
\end{tabular}

1 The Stonyhurst figures were not broadcast, but were received by post.

The agreement between the figures in the last column is satisfactory, and for a preliminary value of the time of origin we may accept 0 h. 3 m. 6 s. G.M.T.

The accompanying diagram (Fig. 1) is taken from

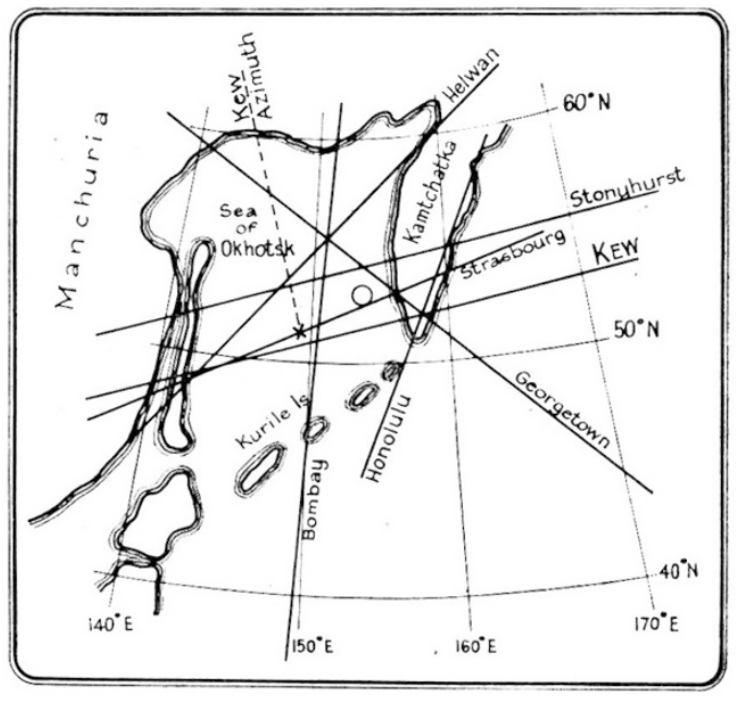

FIG. 1.

the globe on which the epicentral distances were marked off; the arcs in the neighbourhood of the epicentre are shown. From the intersections the epicentre is estimated to have been approximately at the point which is marked with a circle; that is, $53^{\circ} \mathrm{N} ., 153^{\circ} \mathrm{E}$., in the Sea of Okhotsk near the western coast of Kamtchatka. The initial impulse registered by the Kew seismographs (3 components) was sufficiently large to give a trustworthy estimate of the 
bearing, which, together with the epicentral distance, gives $50^{\circ} \mathrm{N}$., $150^{\circ} \mathrm{E}$., for the co-ordinates of the epicentre. This determination is marked by a cross on the diagram. The agreement with the result obtained by using data for the seven stations is as good as could be wished.

The earthquake occurred in a region where such occurrences are frequent. There were considerable earthquakes there on Feb. 16 and Dec. 28, 1927.

\section{University and Educational Intelligence.}

Brrmingham.-Mr. R. G. MacGregor has been appointed lecturer in physiology.

The University Appointments Board has issued its fourth annual report. The report shows a marked increase in the number of new graduates registered, and in the number for whom employment has been found. The demand for men and women with a university training appears to be definitely on the increase, particularly in commerce and industry. It is noted that, of a total of 45 vacancies notified for civil engineers, 44 were for posts abroad. A significant fact is that, of the 64 registered graduates who are unemployed, 50 are seeking appointments in the teaching profession.

CAmBridge.-The official letter conveying the offer of the International Education Board of $£ 700,000$ on condition that within a few years the University finds a further $£ 229,000$, in addition to the $£ 250,000$ already secured for the new Library, has now been received and published. It deals most generously and helpfully with many minor points in connexion with the University, but there is a stipulation that no legacies shall be contributed towards the supplementary sum to be provided by the University, a stipulation not without interest to the University at the moment.

Three further benefactions are announced. A very valuable collection of medical, engineering, electrical, and optical apparatus, bequeathed to the University by the late Sir David Goldsmid-Stern-Salomons, Gonville and Caius College, subject to the life interest of his widow, has now been offered by Lady Salomons to the University. The late Dr. J. W. L. Glaisher, Trinity College, has bequeathed his mathematical books to the University Library, and his collection of china and pottery and other works of art to the Fitzwilliam Museum, with a sum of $£ 10,000$ to be applied in making provision for the care, preservation, and exhibition of the collection. Messrs. Bernard, Reginald, and Kenneth Pretty have offered to the University, at the wish of the late Miss Gwynaeth Pretty, Girton College, her residuary estate of the approximate value of $£ 5000$ for the furtherance of research for the prevention of disease. The diseases in which the testatrix was most interested were those that cripple or disable in childhood.

Dr. R. A. McCance, Sidney Sussex College, has been appointed to the Pinsent-Darwin Studentship in mental pathology.

The Ella Sachs Plotz Foundation is at present assisting research on problems in medicine or surgery, especially group researches on a single problem; for example, for the past five years the general subject of nephritis, and to a lesser extent internal secretion and infection, have been given special consideration. Twenty-one grants were made during 1928, of which thirteen were to workers outside the United States. Applications for grants to be held during 1929-30 must reach the secretary of the executive committee, Dr. Joseph C. Aub, Huntington Memorial Hospital, 695 Huntington Avenue, Boston, Mass., before May 15.

\section{Calendar of Patent Records.}

January 27, I778.- One of the many improvements in the water-closet was due to Joseph Bramah, who was granted a patent for his 'valve' closet on Jan. 27, 1778. Bramah's was not only the pioneer in this type of closet, but it also remained superior in its action to all the many inventions in the same class that followed it. The modern water-closet was first described by Sir John Harington in his "Metamorphosis of Ajax," published in 1596, many years before it came into general use.

January 28, I589.-The saltpetre monopolies of Elizabeth and James I. are notorious from the fact that it was partly the abuse of their privileges by the saltpetre men appointed by the various patentees that led to the popular agitation against monopolies and ultimately. to the Statute of Monopolies of 1623 , but there was at the time a clear case for the establishment of a national source of supply for the manufacture of gunpowder. One of these patents was that granted to George Evelyn, Richard Hills, and John Evelyn on Jan. 28, 1589. Certain districts, notably London, being already covered by other grants, were excluded from its operation, but in 1591 a new grant was issued to the Evelyns that gave them a virtual mono. poly. George Evelyn was the grandfather, and John Evelyn the uncle, of the diarist.

January 28,1724 .- - The faking of expensive materials is not peculiar to the present day. On Jan. 28, 1724, a patent was granted to Robert Redrich and Thomas Jones " as well for staining, veining, spotting, clouding, damasking, and otherwise imitating the various kinds of marble, porphiry, and other rich stones and tortoiseshell, on wood, stone, and earthenware and all and every such goods, wares, utensils, and things, as are cut, made, or fashioned thereout."

January 28 , 1832 . - Steel pen nibs were known early in the last century, but they were not extensively used until James Perry, who had been making them from 1819 onwards, introduced the use of cross slits and apertures between the shoulder and the point. This construction he patented on Jan. 28, 1832. The firm of Perry and Co. was founded in 1829.

January 30, 1808 .- The first band-saw was patented in England by William Newberry on Jan. 30, 1808, but it was thirty years and more before it came into practical use, and it was in France where it was fully developed. The two French patents of Mdlle. Crespin (1846) and M. Perin (1853) may be regarded as the foundation of the modern band-saw.

February I, I 800 .- - One of the earliest patents for a screw propeller for ships was that granted to Edward Shorter on Feb. 1, 1800, for what he called a 'perpetual sculling-machine,' probably intended to enable large vessels to be manceuvred in a calm. Two or more blades similar to the sails of a windmill were mounted on a spar proceeding from any convenient part of the stern of the vessel obliquely downwards until its end dipped into the water, a buoy being provided to prevent it dipping too far. The spar was connected by a Hooke universal joint to a horizontal shaft, to which motion could be given by the capstan worked by man power or by a steam engine. By moving the spar transversely the ship could be steered. The invention is said to have been successfully tried on H.M. Ships Dragon and Superb.

February 3, 18 1 8.-The patent for Jeremiah Chubb's original 'detector' lever lock is dated Feb. 3, 1818. The special feature of this lock was the use of a 'detector' device which came into action immediately if a wrong key with too long a bit were used in an attempt to open the lock, and effectively blocked the bolt until re-set by its proper key. 